\title{
MATHEMATICAL CALCULATION AND EXPERIMENTAL INVESTIGATION OF EXPANDED PERLITE BASED HEAT INSULATION MATERIALS' THERMAL CONDUCTIVITY VALUES
}

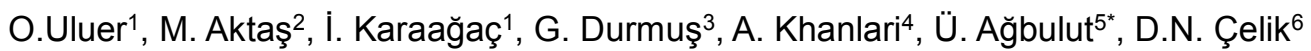

\begin{abstract}
Thermal resistance can be increased by using proper heat insulation materials. Traditional heat insulation materials do not stand all desired properties. Thus, developing new heat insulation materials is very important. In this study, expanded perlite based heat insulation material was developed as an alternative to the traditional insulation materials. The composition of the developed material was designed and prepared using the theoretical thermal conductivity prediction models. The prepared material was molded in a rectangular shape panel. Thermal conductivities of panels were measured experimentally and the results were compared with the calculated results. Also, the results showed that the developed panels can be used for heat insulation applications. On the other hand, the closest model to the experimental results is the parallel model whose average deviation is $4.22 \%$ while the farthest model is the Cheng and Vachon model whose average deviation is $12.43 \%$. It is obtained that parallel and series models are generally in good agreement with the experimental results. Nevertheless, it is seen some deviations between experimental and theoretical calculation results. The theoretical prediction models do not include any processing conditions such as molding and curing. It is thought that these deviations have originated because of the missing processing parameters in theoretical prediction models. As a result of experimental studies, the lowest thermal conductivity value of expanded perlite based panels was obtained $43.5 \mathrm{~mW} / \mathrm{m} . \mathrm{K}$. Consequently, the heat transfer coefficient of the panels containing expanded perlite can be calculated nearly by the parallel method.
\end{abstract}

\section{Keywords: Expanded Perlite, Insulation Technology, Heat Transfer, Thermal Conductivity}

\section{INTRODUCTION}

It is clear that reducing the total energy losses from buildings has a big influence on total greenhouse gas emissions. Thermal insulation of buildings does not only conserve the energy and environment, but also insulates the sound, protects against the fire and decreases the energy costs. Traditional heat insulation materials are used in thicker or multiple layers, which resulted in more complex building details, an adverse net to gross floor area and possible heavier load bearing constructions [1]. Therefore, development of the new technologies and materials are gaining importance.

Perlite is one of the best natural insulation materials. It is obtained from pumice, which is a glassy form of rhyolitic or dacitic magma. It contains $2-5 \%$ water [2] and it can be expanded for micro porous cellular structure formation. The expansion is occurred due to the heating of existing water in perlite at about $649-816^{\circ} \mathrm{C}$ [3]. Also, expanded perlite has some superior properties such as low density, low thermal conductivity, good chemical stability, non-flammable, sound absorbsion and non-toxic [4]. Thermal properties of expanded perlite show that it can be used as thermal insulation materials [5].

In addition, perlite can be used as an additive in various mixtures or as a main component for composite e.g. materials for blocks, perlite/sodium silicate boards, roof insulation panels made of perlite material, fiber reinforced perlite composites, building boards made of fiber/asphalt coated perlite, fiber reinforced sodium silicate/perlite composite band light weight concrete [6]. However, their applications as the main constituent of composites have been limited due to relatively poor mechanical properties; large absorption and the low strength [3]. The new process appears to be capable of extending the limitation of perlite applications, allowing to manufacture samples for exploring novel mechanical behavior of consolidated expanded perlite particles [7]. Also, This paper was recommended for publication in revised form by Regional Editor Ahmet Selim Dalkılıç

${ }^{1}$ Department of Manufacturing Engineering, Gazi University, Ankara, TURKEY

${ }^{2}$ Department of Energy Systems Engineering, Gazi University, Ankara, TURKEY

${ }^{3}$ Department of Civil Engineering, Gazi University, Ankara, TURKEY

${ }^{4}$ Natural and Applied Science Institute, Gazi University, Ankara, TURKEY

${ }^{*}$ Department of Mechanical and Manufacturing Engineering, Düzce University, Düzce, TURKEY

${ }^{6}$ Department of Civil Engineering, Antalya Bilim University, Istanbul, TURKEY

*E-mail address: umitagbulut@duzce.edu.tr

Manuscript Received 2 March 2017, Accepted 21 July 2017 
it is non-combustible, water-resistant and sufficiently inexpensive for developing building materials. The conventional perlite insulation board is made of an aqueous slurry of expanded perlite particles, binder, and additives (fibers, waterproofing agents, fire retardant, etc.), that is formed into a board by a Fourdrinier process and subsequently dried. Another type of board production is suggested, with mixing expanded perlite particles and sodium or sodium-potassium silicate, pressing the mixture in a mold and drying the pressed board. Conventional and microwave techniques are possible for drying such a board [8].

There are some studies about heat insulation material. Al-Homoud investigated performance properties and practical applications of common building thermal insulation materials. Also, an overview of the basic principles of thermal insulation and to survey the most commonly used building insulation materials, their performance properties and proper applications were presented. As a result, the proper use of thermal insulation in buildings does not only contribute in reducing the required air-conditioning system size but also in reducing the annual energy cost [9].

Papadopoulos studied new thermal insulation materials aiming for future developments. Differences between various types of insulation materials are investigated. Also, comparative evaluation of state of art insulation material with respect to their physical properties, health and environmental properties, applicability in specific building elements and structural problems, and their cost have been done. The author indicates that the thermal properties of the materials have not improved significantly of the last decade, but a series of other features, like reaction to fire and moisture or mechanical properties have improved [10].

Kylili and Fokaides investigated methodologies for selection of thermal insulation materials for costeffective, sustainable, and energy-efficient retrofitting. This paper gives comprehensive information in the field of thermal insulation materials. The study showed that the definition of suitable thermal insulation materials for energy conservation of buildings should reveal both environmental and economic approaches. Environmental and economic conditions are important factors for thermal insulation materials [11].

Pargana et al. evaluated the environmental impacts and the consumption of renewable and non-renewable primary energy on the production of conventional thermal insulation materials: extruded and expanded polystyrene, polyurethane, expanded cork agglomerate and expanded clay lightweight aggregates [12].

According to literature studies, it is seen that by using expanded perlite in thermal insulation material, it is possible to produce a material capable of responding to the desired characteristics in the industry. For this reason, many researchers have worked on this field and are still working on it. Especially, there are some researches that focused on utilization of expanded perlite to improve thermal properties of materials. Taherishargh et al. studied thermally treated expanded perlite-aluminum synthetic mechanical properties, and deformation behavior. The effect on the mechanical properties of heat-treated is greater specimens than untreated specimens. As a result, heat treated foams were deformed more homogeneous and small density increase in heat treated sample has significantly increased the strength [13].

Arifuzzaman and Kim studied expanded perlite based insulation material and investigated experimentally their properties. Sodium silicate was used as binder. Authors emphasized that depending on the increasing of compression pressure, the density increased and density of the panel was not depending on the size of the expanded perlite grain [3].

Binici and Kalaycı produced perlite based heat insulating material. The usability of expanded perlite as a heat insulating material was investigated. The thermal conductivity of produced samples was determined. According to results, as the ratio of expanded perlite increases, specific bulk density decreases. As the ratio of air in the concrete increases and as a result of this, thermal conductivity values decrease. The thermal conductivity of expanded perlite - based material was found between the 61.8 - $189 \mathrm{~mW} / \mathrm{m} . \mathrm{K}$ [14].

Argunhan et al. investigated of the thermal and acoustic performance of perlite based building materials. Turkey where holds a large portion perlite reserves in the world. So, using of perlite in insulation sector, which has advantages in terms of heat and sound insulation, will make an important contribution to the national economy. Normal aggregates replaced by expanded perlite aggregates at different volume fractions such as $10 \%, 20 \%, 30 \%$, $40 \%, 50 \%$ and $60 \%$ of the total aggregate volume. Mechanical and thermal tests were all conducted and the hot disk method was used to establish thermal property values of concrete samples. The results of the experimental studies show that the compressive strength and density decreases, the heat and sound insulation features improved by increasing in perlite content. In addition, it is determined that the thermal conductivity coefficient of the sample produced using normal aggregate is $2075 \mathrm{~mW} / \mathrm{m} . \mathrm{K}$ and the thermal conductivity coefficient of the sample 
produced by using $60 \%$ expanded perlite aggregate is $520 \mathrm{~mW} / \mathrm{m} . \mathrm{K}$, which is inversely proportional to the aggregate ratio and thermal conductivity coefficient [15].

Topçu and Işı1kdağ studied concrete properties by adding expanded perlite. They focused on the extracellular and exchange rates of cement types containing expanded perlite aggregates. When more expanded perlite aggregate was used, the strength was reduced and the material properties were getting better. The compressive strength, tensile splitting strength, and dynamic elastic modulus increased with increasing dosage $[16]$.

Demirboğa and Gül studied thermal conductivity and compressive strength of expanded perlite aggregate concrete with mineral admixtures. They studied the influence of two admixtures on expanded perlite aggregate concrete. Both silica fume and fly ash were added as replacement for cement by decreasing the cement weights in the ratios of 10, 20 and $30 \%$ by weight. The obtained results showed that, the thermal conductivity decreased with the increase of silica fume and fly ash as replacement for Portland cement up to 14 and $18 \%$, respectively. The results showed that the lowest value of thermal conductivity of sample is $155.3 \mathrm{~mW} / \mathrm{m} . \mathrm{K}$ [17].

Çelik et al. investigated on the usability of the expanded perlite aggregate in the manufacturing of building materials. While the sample was prepared, the most effective values for sample production were determined by changing the design parameters such as compression pressure, cured temperature, curing time. As a result of this study, the lowest unit weight of the samples with a water/solid ratio of 1.0, produced at 50 bar pressure and cured at $200{ }^{\circ} \mathrm{C}$ for 1 hour, had a weight of $522.5 \pm 48.3 \mathrm{~kg} / \mathrm{m}^{3}$ and a maximum compressive strength of $2 \mathrm{MPa}$. It has been seen that scientific studies on the production of building materials with high strength and low unit weight values can be made by using different binders in the following stages [18].

Also, some researchers investigated binders. Vaou and Panias studied ability of geopolymerization technology for production of thermal insulating foamy inorganic polymers utilizing as solid raw material ultrafine perlite which is a by-product from comminution and sizing operations of perlite exploitation. The effect of addition of the blowing agent on the thermophysical properties of thermal insulating materials was studied and these properties are compared with the ones of the commercial thermal insulating materials indicating the high potentiality for the development of this new family of inorganic polymeric materials. Produced from non-expanded perlite foamy geopolymers proved to be very good thermal insulating materials.In comparison with the commercial organic (expanded and extruded polystyrene) and inorganic (glass and stone wool) thermal insulating materials, the foamy geopolymers from perlite have almost similar thermal conductivity $(300 \mathrm{~mW} / \mathrm{m} . \mathrm{K})$ and superior compressive strength ( $780 \mathrm{kPa}$ at $2 \%$ deformation) and a fracture behavior resembling the one of rocks [19].

Gharzouni et al. studied the effect of the reactivity of alkaline solution and metakaolin on geopolymer formation. They prepared mixtures using two different alkali solutions and 4 different types of metakaolin. The alkali solution was formed by dissolving potassium hydroxide and amorphous silica in water. It has been observed that the solution using potassium silicate and potassium hydroxide gave higher mechanical properties than the solution using sodium silicate and sodium hydroxide [20].

Ikeda investigated consolidation of mineral powders for the use of materials with geopolymer binder technology. These materials are raw materials, inactive filler and geopolymer solution. The raw materials are needed to dissolve during plasticizing when sodium silicate solution is used as a binder and alkali hydroxide solution is used as an alkali activator. [21].

Shastri and Kim studied new building material for the consolidation of starch binder-expanded perlite particles. Produced perlite foams strength and the pressure modulus were compared to the gypsum for foam density. When using perlite foam produced with foamed gypsum, it was observed that the compressive strengths were compatible with 0.3 relative density [22].

Curing conditions are one of the important parameters to achieve desired properties such as binding, researches focused on different curing methods for expanded perlite-based heat insulation panels.

Astutiningsih et al. produced a geopolymer with a high content of $\mathrm{CaO}(41 \%)$ from Australia slag at $60^{\circ} \mathrm{C}$ for 24 hours. According to the results, the compressive strength of geopolymer samples did not exceed $30 \mathrm{MPa}$. Pressure constants of the geopolymers increased with decreasing water content in the sodium silicate solution [23].

Tian et al. studied the effect of pressing pressure and curing temperature on mechanical properties of expanded perlite-based thermal insulation boards. They indicate that $0.38 \mathrm{MPa}$ of pressing pressure and $105^{\circ} \mathrm{C}$ temperature is suitable for expanded perlite-based thermal insulation boards [24].

Skubic et al. simulated the curing temperature of the insulation panels made of expanded perlite with a mathematical model. Then experimental results and simulated values were compared. The shrinkage of the heat- 
treated panels was occurred. Thermal conductivity coefficient of the expanded perlite was calculated as 45 $\mathrm{mW} / \mathrm{m} . \mathrm{K}$. As the sodium silicate ratio decreased, the curing temperature increased [25].

Skubic et al. studied the microwave drying of expanded perlite based insulation panels. It is very difficult and long to dry a material with heat insulation properties by conventional methods. The microwave penetrates into the product and provides quick drying. Microwave drying has been found to be a suitable drying method for expanded perlite based insulation panels. As a result, if the drying process is not terminated at the right time, the product temperature will increase rapidly and the product will be damaged [8].

As it is seen from literature, the studies which are related to insulation panels based expanded perlite are focused on consolidation properties, binders and curing conditions generally. However, there are several studies about how to use expanded perlite as insulation panel and how to reduce thermal conductivity of expanded perlite. In investigated studies, it is seen that the lowest thermal conductivity value was $45 \mathrm{~mW} / \mathrm{m} . \mathrm{K}$.

In this study, alternative to the traditional insulation materials, expanded perlite based heat insulation panels were developed. Also, thermal conductivity of expanded perlite panel was measured experimentally and the results were compared with the calculated results.

\section{MATERIAL AND METHODS}

The manufacturing procedure of expanded perlite based thermal insulation material was given in Figure 1.

The total reserve in the world is 7.700 million tones and 5.700 million tones (74\%) of it are in Turkey [26]. In the first stage, expanded perlite was supplied from various areas of Turkey. However, it has been determined that despite the inhomogeneous composition of expanded perlite from region to region, there are small differences in terms of thermal conductivity. Therefore, suitable expanded perlite in terms of thermal conductivity was used to obtain the desired physical and chemical properties. Its chemical and physical properties were given in Table 1 and Table 2.

In the second stage, the mortar has been prepared using $\mathrm{Na}_{2} \mathrm{SiO}_{3}-5 \mathrm{H}_{2} \mathrm{O}$ and $\mathrm{NaOH}$ mixture as a binder. Mixing proportions were determined by considering literature studies. To obtain better binder mixture, vol.4-12\% $\mathrm{Na}_{2} \mathrm{SiO}_{3}-5 \mathrm{H}_{2} \mathrm{O}$ and $\mathrm{NaOH}$ solution $(8-14 \mathrm{M})$ was prepared and mixed by laboratory mixer for 20 minutes. Mixing has been continued for a further 10 minutes after adding hydrogen peroxide $\left(\mathrm{H}_{2} \mathrm{O}_{2}\right)$ to obtain the final binder mixture. Expanded perlite and binder were mixed together by the aid of mechanical mixer throughout 10 mins and the mortar was obtained (Figure 2).

The prepared mortar was poured into the mold to a height of $100 \mathrm{~mm}(500 \times 300 \times 100 \mathrm{~mm})$ and compressed to an ultimate panel thickness of $50 \mathrm{~mm}(500 \times 300 \times 50 \mathrm{~mm})$ by the hydraulic press (Figures 3-4). The sample was held for 3 minutes under constant press force $(2500 \mathrm{~N})$. Finally, the test sample was obtained in $300 \times 300 \times 50$ millimeters dimensions by cutting the molded panel.

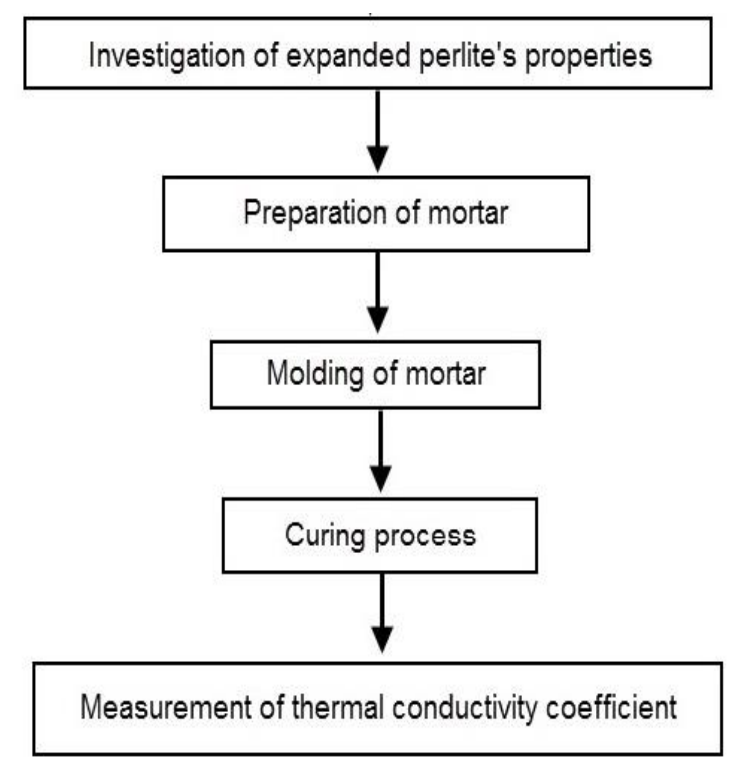

Figure 1. Experimental procedure steps 


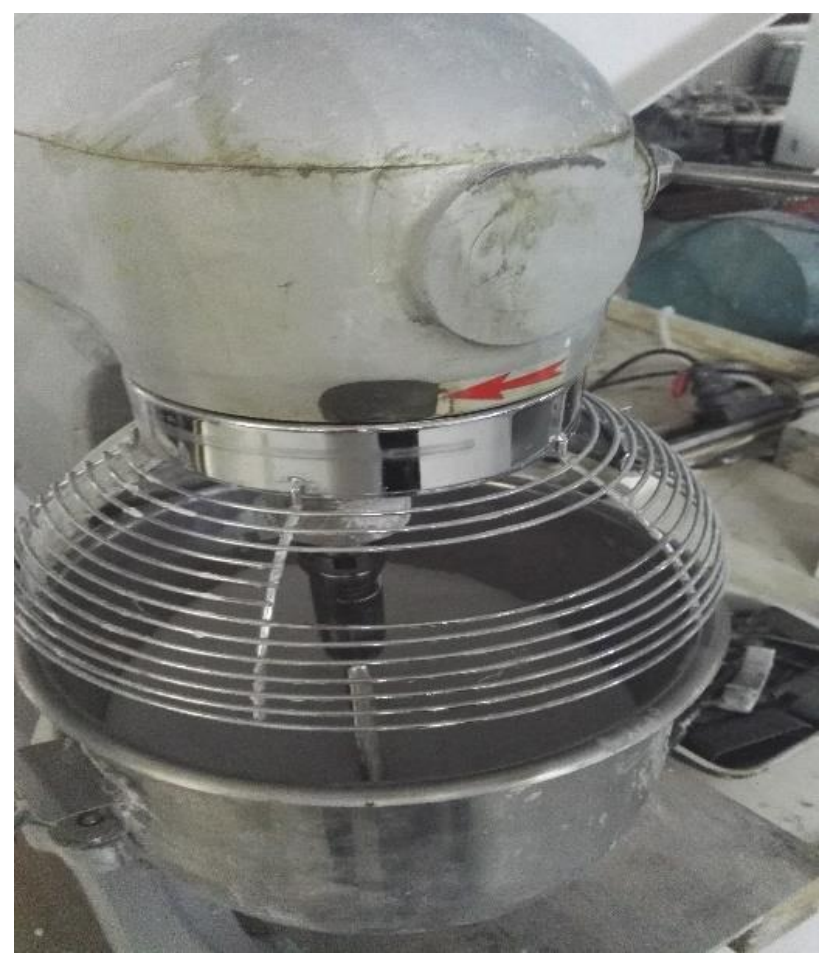

Figure 2. Preparation of mortar

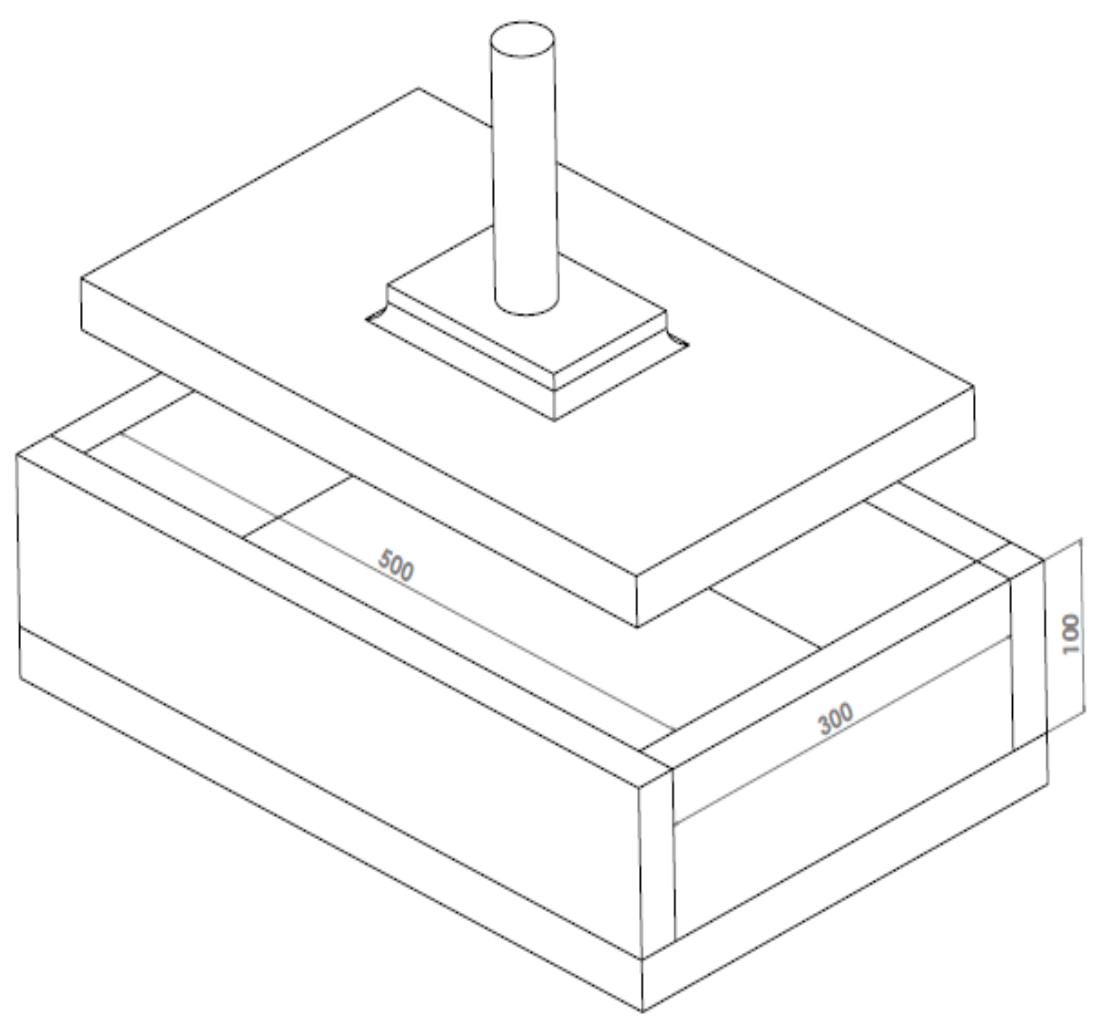

Figure 3. General view of mold

The obtained sample was cured at $105^{\circ} \mathrm{C}$ in a drying oven during 14 hours (Figure 5). The drying oven properties were given in Table 3. Before and after molding and curing operations, the first and the latest mass of sample was measured. The cured sample was allowed to cool at room temperature $\left(25^{\circ} \mathrm{C}\right)$ for 3 hours. 


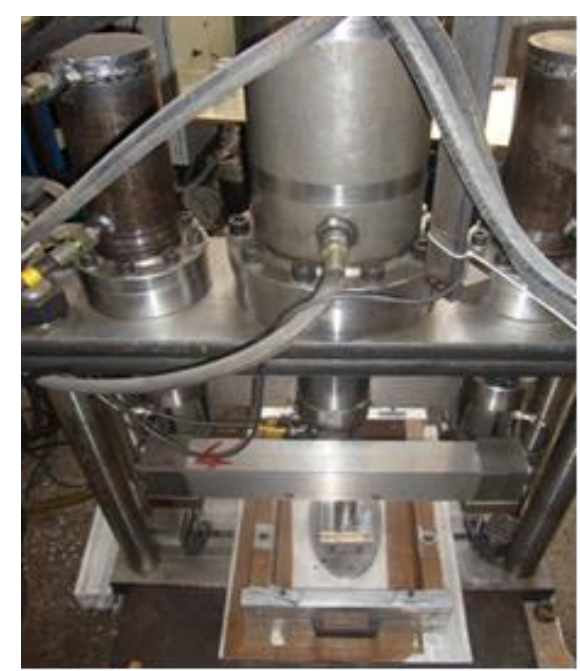

Figure 4. General view of hydraulic press

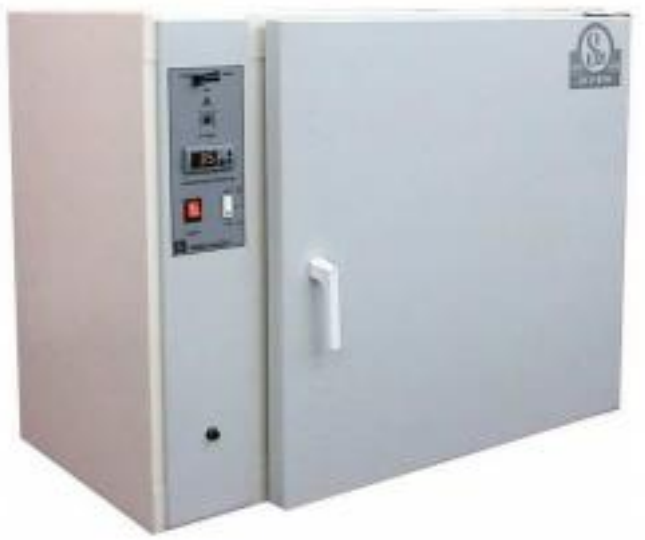

Figure 5. Drying oven

After the curing step was completed, the sample was ready to measure the thermal conductivity. Thermal conductivity of cooled sample was measured by HFM 300 device (Figure 6). The properties of thermal conductivity testing device were given in Table 4.
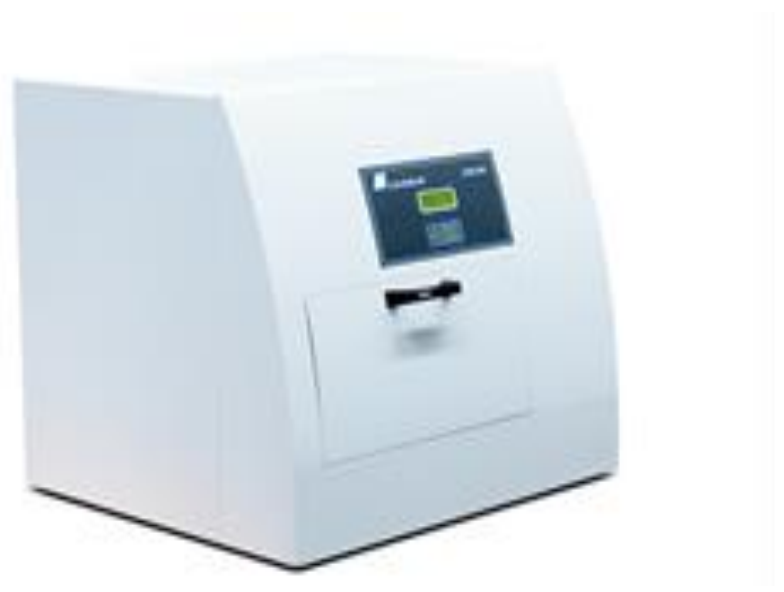

Figure 6. LINSEIS HFM300 heat flow meter machine 
Table 1. Chemical properties of expanded perlite

\begin{tabular}{|c|c|}
\hline Content & wt.\% \\
\hline $\mathrm{SiO}_{2}$ & 74 \\
\hline $\mathrm{Al}_{2} \mathrm{O}_{3}$ & 14.33 \\
\hline $\mathrm{K}_{2} \mathrm{O}$ & 4.95 \\
\hline $\mathrm{MgO}$ & 0.28 \\
\hline $\mathrm{CaO}$ & 0.50 \\
\hline $\mathrm{Fe}_{2} \mathrm{O}_{3}$ & 0.97 \\
\hline
\end{tabular}

Table 2. Physical properties of expanded perlite

\begin{tabular}{|c|c|}
\hline Properties & Values \\
\hline Density, $\mathrm{kg} / \mathrm{m}^{3}( \pm 10 \%)$ & $45-50$ \\
\hline Grain Size, $\mathrm{mm}$ & $0-0.5$ \\
\hline Thermal Conductivity, at $25^{\circ} \mathrm{C}, \mathrm{mW} / \mathrm{m} . \mathrm{K}$ & $40-65$ \\
\hline $\mathrm{pH}$ & $4-9$ \\
\hline
\end{tabular}

Table 3. The properties of drying oven

\begin{tabular}{|c|c|}
\hline Properties & Values \\
\hline Capacity, $\mathrm{L}$ & 250 \\
\hline Ambient temperature, ${ }^{\circ} \mathrm{C}$ & $0-250$ \\
\hline Thermostat accuracy, ${ }^{\circ} \mathrm{C}$ & 0.1 \\
\hline Internal temperature difference, ${ }^{\circ} \mathrm{C}$ & \pm 2 \\
\hline Circulation & Air \\
\hline
\end{tabular}

Table 4. The properties of thermal conductivity testing device

\begin{tabular}{|c|c|}
\hline Specification & Values \\
\hline Temperature Range (Plates), ${ }^{\circ} \mathrm{C}$ & 0 to 40 \\
\hline Temperature control (Plate) & Peltier \\
\hline Thermal resistance measuring range, $\mathrm{m}^{2} . \mathrm{K} / \mathrm{W}$ & 0.1 to 8.0 \\
\hline Thermal conductivity measuring range, $\mathrm{mW} / \mathrm{m} . \mathrm{K}$ & 1 to 2500 \\
\hline Accuracy, $\%$ & \pm 1 to 3 \\
\hline Variable contact pressure, $\mathrm{kPa}$ & 0.25 \\
\hline
\end{tabular}

The processing stages of the heat insulation panel were completed and results were compared with theoretical models.

\section{THE PREDICTION OF THERMAL CONDUCTIVITY}

Thermal conductivity is the most important property of heat insulation materials; however, because of the measuring limitations, difficulties during sample preparations and additional costs, measuring is not preferred way for thermal conductivity. There are many models available to predict thermal conductivity of composite materials theoretically. Some of them are series and parallel, geometric mean, Maxwell, Cheng and Vachon, Lewis and Nielse models. Some of these models just include the volumetric ratio and the thermal conductivity of composite components to predict thermal conductivity. Theoretical calculations were performed for all of these models, but series model, parallel model, and geometric mean model give more accurate results for perlite based heat insulation panel.

Series and Parallel models:

These models are the simplest methods to predict the thermal conductivity of composite materials. These models were given as bellow [27]: 


$$
\begin{aligned}
& k_{e(\text { seris })}=\left[\left(V_{d} / k_{d}\right)+\left(\varepsilon / k_{s}\right)\right]^{-1} \\
& k_{e(\text { parallel })}=\left(V_{d} \cdot k_{d}\right)+\left(\varepsilon \cdot k_{s}\right)
\end{aligned}
$$

$\mathrm{k}_{\mathrm{s}}, \mathrm{k}_{\mathrm{d}}, \mathrm{Vd}$ and $\varepsilon$ are thermal conductivity of matrix, thermal conductivity of fiber, volumetric ratio of matrix and volumetric ratio of fiber respectively.

\section{Geometric Mean model:}

In this model the volumetric ratio and thermal conductivity of components used to predict the thermal conductivity $[28,29]$.

$$
k_{e}=\left(k_{s}\right)^{\varepsilon} k_{d}^{(1-\varepsilon)}
$$

\section{Maxwell Model}

Maxwell obtained a simple relationship [30] for the effective thermal conductivity of homogeneous spheres randomly distributed and non-interacting in a homogeneous environment:

$$
k_{e}=k_{s}\left[\frac{2 k_{s}+k_{d}-2\left(k_{s}-k_{d}\right) \cdot V_{d}}{2 k_{s}+k_{d}+\left(k_{s}-k_{d}\right) \cdot V_{d}}\right]
$$

Here, $\mathrm{Vd}$ is the volumetric ratio of the dispersed phase and can be expressed as $(1-\varepsilon)$. This model predicts the effective thermal conductivity very well at low dispersion fill phases. However, in materials with highconcentration filler phases, the filler particles form transmission chains either in contact with each other or in the direction of heat flow. Therefore, it is seen that this model predicts low effective thermal conductivity. It is stated that one of the two components of this model can yield reliable results when the porosity is not more than 0.25 and the thermal conductivity rate $(\mathrm{kd} / \mathrm{ks})$ is not more than 10 [31]. It identifies Maxwell model with $\mathrm{j}$ parameter [32]. Here, Maxwell-Hamilton model is given by putting (j-1) coefficient instead of 2 in Maxwell model. There is also a modified Maxwell model, which is available among flexible models. In this case, the Maxwell model uses the $[2 /(1-j 2)]$ coefficient instead of $2[33,34]$. Although it is the empirical parameter, $\mathrm{j}$ is a measure of the nature of the heat transfer paths in the material. This model is a suitable model for materials with infrequent distributions. This model has been investigated for differently distributed phase shapes and the corresponding effective thermal conductivity results have been obtained at high ratios of sphere-like filler phases [35].

The Maxwell - Eucken model, among similar models, is one of the well-known models. There are two forms of this model. These are Maxwell-Eucken equations 1 and 2. Here is Maxwell - Eucken 2 model;

$$
k_{e}=k_{d}\left[\frac{2 k_{d}+k_{s}-2\left(k_{d}-k_{s}\right) \cdot \varepsilon}{2 k_{s}+k_{d}+\left(k_{s}-k_{d}\right) \cdot V_{d}}\right]
$$

ks and kd are the thermal conductivities of the continuous and the dispersed phase, respectively. The MaxwellEucken 1 equation is given as the lower limit of isotropic external porous materials and Maxwell-Eucken 2 model is defined as the upper limit for isotropic inner pore materials [36].

\section{Nielsen Model}

According to the Nielsen model, the thermal conductivity of a porous material is related to the thermal conductivity of the continuous medium and the filler phase (ks and kd) [37].

$$
k_{e}=k_{s}\left[\frac{\left(1+w B V_{d}\right)}{\left|1-C B V_{d}\right|}\right]
$$

Here, parameters B and C are shown as follows: 


$$
\begin{gathered}
B=k_{s}\left[\frac{\left.\left(\left(k_{d} / k_{s}\right)-1\right)\right)}{\left.\left(\left(k_{d} / k_{s}\right)+W\right)\right)}\right] \\
C=1+\left[\left(1-V_{M}\right) / V_{M}{ }^{2}\right] V_{d}
\end{gathered}
$$

VM is the maximum packing rate of the fill phase. $w$ is a dimensional shape factor depending on the geometry of the filler particles. The $w$ parameter is considered to be related to the generalized Einstein coefficient ( $w=k . E$ 1). The $w$ value is given as 2 and 0.5 for some particles [38].

\section{Cheng and Vachon Model}

Cheng and Vachon are discontinuous phases with a parabolic distribution of additive material. In two different composite materials, the additive is expressed in closed form depending on the volumetric ratio of the material [39].

$\mathrm{k}_{\mathrm{s}}>\mathrm{k}_{\mathrm{d}} \rightarrow$

$$
\begin{gathered}
\frac{1}{k_{e}}=\frac{2}{\sqrt{C_{2}\left(k_{d}-k_{s}\right)\left[k_{s}+C_{1}\left(k_{d}-k_{s}\right)\right]}} \tan ^{-1} \frac{C_{1}}{2} \sqrt{\frac{C_{2}\left(k_{d}-k_{s}\right)}{k_{s}+C_{1}\left(k_{d}-k_{S}\right)}}+\frac{1-C_{1}}{k_{s}} \\
k_{d}>k_{s} \rightarrow \frac{1}{k_{e}}=\frac{1}{\sqrt{C_{2}\left(k_{d}-k_{s}\right)\left[k_{s}+C_{1}\left(k_{d}-k_{s}\right)\right]}} \ln \frac{\left(\sqrt{\left(k_{s}+C_{1}\left(k_{d}-k_{s}\right)\right.}\right)+\frac{C_{1}}{2} \sqrt{C_{2}\left(k_{d}-k_{s}\right)}}{\sqrt{\left(k_{S}+C_{1}\left(k_{d}-k_{s}\right)\right.}-\frac{C_{1}}{2} \sqrt{C_{2}\left(k_{d}-k_{s}\right)}}+\frac{1-C_{1}}{k_{s}}
\end{gathered}
$$

In both equations, $\mathrm{C} 1$ and $\mathrm{C} 2$ are as follows:

$$
\begin{aligned}
& C_{1}=\sqrt{\left(3 V_{d}\right) / 2} \\
& C_{2}=-4 \sqrt{2 /\left(3 V_{d}\right)}
\end{aligned}
$$

Uncertainty analysis

Errors and uncertainties depend on many factors. These are instrument selection, test conditions-planning, calibration, reading, and connection type-points of measurement probes. Uncertainty analysis is an effective method to evaluate the experimental results. Total uncertainty values are calculated using the following equation [40]

$$
W_{R}=\left[\left(\frac{\partial R}{\partial x_{1}} w_{1}\right)^{2}+\left(\frac{\partial R}{\partial x_{2}} w_{2}\right)^{2}+\ldots \ldots \ldots \ldots+\left(\frac{\partial R}{\partial x_{n}} w_{n}\right)^{2}\right]^{1 / 2}
$$

After the experiment, uncertainty analysis is performed to determine the error rates of the experimental data. Thermal conductivity values of samples were measured by HFM 300 device (accuracy $\pm 1-3 \%$ ).

\section{RESULTS AND DISCUSSION}

At the beginning of the study, various commercial expanded perlite types from the different regions were supplied. Then thermal conductivities of each one were measured. After that, the species with lowest thermal conductivity was used to prepare sample panels in this study. Figure 7 shows the experimental and thermal conductivity prediction model results for thermal conductivity of panels which prepared from three various expanded perlites.

The molded samples without binder were tested to determine and choose the most appropriate theoretical thermal conductivity prediction model. Test results were given in Figures 7-8. 


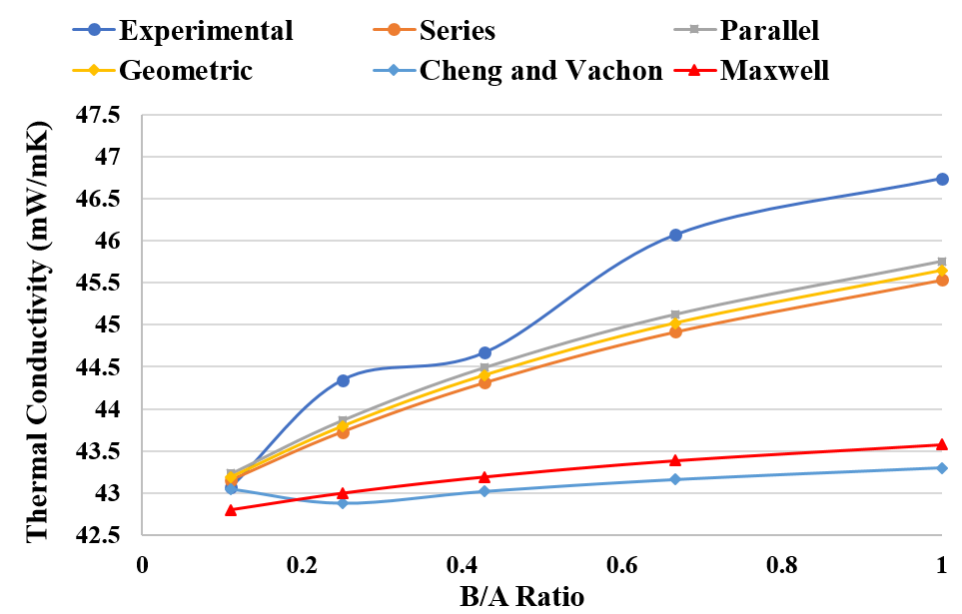

Figure 7. Thermal conductivity of two various mixture expanded perlite panels (commercial A and B samples)

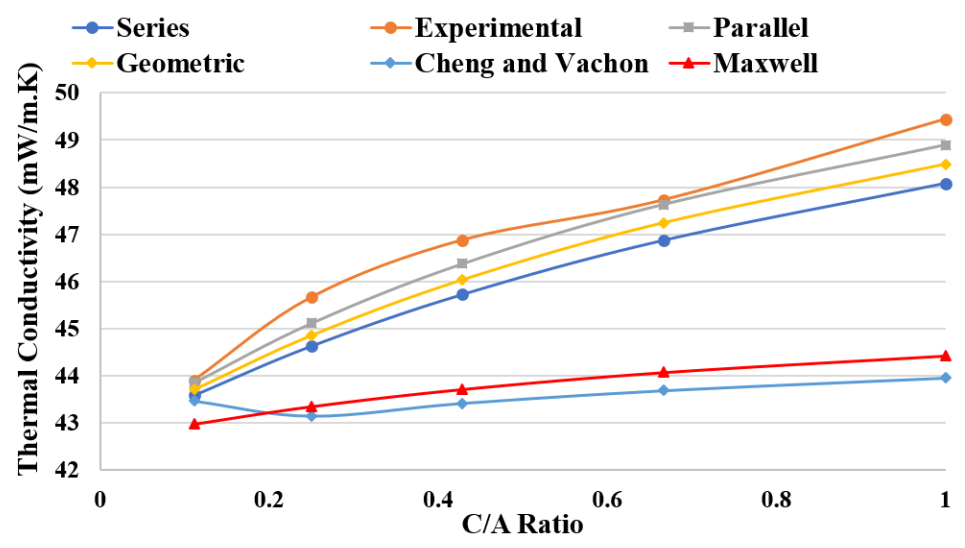

Figure 8. Thermal conductivity of two various mixture expanded perlite panels (commercial A and C samples)

More accurate results were obtained when the series, parallel theoretical prediction models used for calculations. After this stage, the prepared panel mortars with binder were molded. Then the molded panels were cured. After the curing process, thermal conductivity of samples was measured. The cured panel is shown in the Figure 9. The measured and theoretical results were given in Table 5.

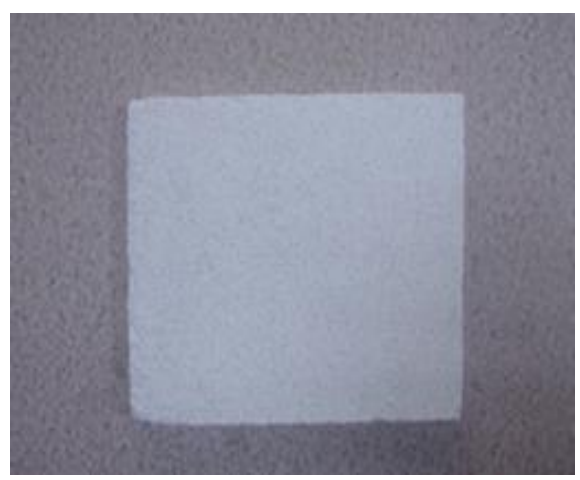

Figure 9. Molded sample

Generally, experimental thermal conductivity values are in good agreement with theoretical values. As it can be seen in Table 5, thermal conductivity values obtained from parallel model are closer to experimental results than the other models especially for the first 3 samples. Maxwell and Cheng and Vachon model's deviations are so big except for sample 4 . 
It is known that the composition of binder, molding force and expanded perlite properties affect the values of thermal conductivity. However, the theoretical prediction models do not include any parameter/coefficient to represent the effect of processing condition such as curing and molding conditions. Therefore, differences were observed between the thermal conductivity prediction model results and experimentally measured thermal conductivity results. For this reason, new theoretical thermal conductivity prediction models should be developed by considering the other effective parameters.

For the values of the thermal conductivity measured in the experimental study, uncertainty values were calculated between the $\pm 1.141 \%$ and $\pm 3.162 \%$ using Eq. (13). These uncertainty ranges are in an acceptable level.

Obtained thermal conductivity values were changed between the $43.35 \mathrm{~mW} / \mathrm{m} . \mathrm{K}$ and $71.22 \mathrm{~mW} / \mathrm{m} . \mathrm{K}$. The obtained results are in good agreement when compared with literature, $61.8-189 \mathrm{~mW} / \mathrm{m} . \mathrm{K}$ [14], $45 \mathrm{~mW} / \mathrm{m} . \mathrm{K}$ [25].

Table 5. Experimental and theoretical results

\begin{tabular}{|c|c|c|c|c|}
\hline $\begin{array}{l}\text { Sample No } \\
\text { Ingredient }\end{array}$ & $\begin{array}{c}\text { Sample 1 } \\
\text { (vol. 88-90\% E.P } \\
+\% 10-12 \text { vol } \\
\text { binder) }\end{array}$ & $\begin{array}{c}\text { Sample } 2 \\
\text { (vol 90-92 \%E.P } \\
+\% \text { \%-10vol binder) }\end{array}$ & $\begin{array}{c}\text { Sample } 3 \\
\text { (\%92-94vol E.P } \\
+\% \text { \%-8vol binder })\end{array}$ & $\begin{array}{c}\text { Sample } 4 \\
\text { (\%94-96vol E.P } \\
+ \text { \%4-6vol binder) }\end{array}$ \\
\hline Experimental & $71.22 \mathrm{~mW} / \mathrm{m} . \mathrm{K}$ & $56.77 \mathrm{~mW} / \mathrm{m} . \mathrm{K}$ & $51.23 \mathrm{~mW} / \mathrm{m} . \mathrm{K}$ & $43.35 \mathrm{~mW} / \mathrm{m} . \mathrm{K}$ \\
\hline Series model & $\begin{array}{c}66.71 \mathrm{~mW} / \mathrm{m} . \mathrm{K} \\
(\sim 6.3 \% \text { deviation })\end{array}$ & $\begin{array}{c}44.72 \mathrm{~mW} / \mathrm{m} . \mathrm{K} \\
(\sim 2.1 \% \text { deviation })\end{array}$ & $\begin{array}{c}45.87 \mathrm{~mW} / \mathrm{m} . \mathrm{K} \\
(\sim 4.6 \% \text { deviation })\end{array}$ & $\begin{array}{c}40.21 \mathrm{~mW} / \mathrm{m} . \mathrm{K} \\
(\sim 7.2 \% \text { deviation })\end{array}$ \\
\hline $\begin{array}{l}\text { Parallel } \\
\text { model }\end{array}$ & $\begin{array}{l}70.52 \mathrm{~mW} / \mathrm{m} . \mathrm{K} \\
(\sim 1 \% \text { deviation })\end{array}$ & $\begin{array}{l}53.35 \mathrm{~mW} / \mathrm{m} . \mathrm{K} \\
(\sim 6 \% \text { deviation })\end{array}$ & $\begin{array}{c}49.40 \mathrm{~mW} / \mathrm{m} . \mathrm{K} \\
(\sim 3.6 \% \text { deviation })\end{array}$ & $\begin{array}{c}40.60 \mathrm{~mW} / \mathrm{m} . \mathrm{K} \\
(\sim 6.3 \% \text { deviation })\end{array}$ \\
\hline $\begin{array}{c}\text { Geometric } \\
\text { Mean model }\end{array}$ & $\begin{array}{c}68.42 \mathrm{~mW} / \mathrm{m} . \mathrm{K} \\
(\sim 3.9 \% \text { deviation })\end{array}$ & $\begin{array}{c}45.34 \mathrm{~mW} / \mathrm{m} . \mathrm{K} \\
(\sim 20.1 \% \text { deviation })\end{array}$ & $\begin{array}{c}45.32 \mathrm{~mW} / \mathrm{m} . \mathrm{K} \\
(\sim 11.5 \% \text { deviation })\end{array}$ & $\begin{array}{c}38.23 \mathrm{~mW} / \mathrm{m} . \mathrm{K} \\
(\sim 11.8 \% \text { deviation })\end{array}$ \\
\hline $\begin{array}{c}\text { Cheng and } \\
\text { Vachon model }\end{array}$ & $\begin{array}{c}66.5 \text { mW/M.k } \\
(\sim 6.6 \% \text { deviation })\end{array}$ & $\begin{array}{c}45.61 \mathrm{~mW} / \mathrm{m} . \mathrm{K} \\
(\sim 24.5 \% \text { deviation })\end{array}$ & $\begin{array}{c}44.02 \mathrm{~mW} / \mathrm{m} . \mathrm{K} \\
(\sim 14.1 \% \text { deviation })\end{array}$ & $\begin{array}{c}41.38 \mathrm{~mW} / \mathrm{m} . \mathrm{K} \\
(\sim 4.5 \% \text { deviation })\end{array}$ \\
\hline $\begin{array}{c}\text { Maxwell } \\
\text { Model }\end{array}$ & $\begin{array}{c}62.47 \mathrm{~mW} / \mathrm{m} . \mathrm{K} \\
(\sim 12.3 \% \text { deviation })\end{array}$ & $\begin{array}{c}43.55 \mathrm{~mW} / \mathrm{m} . \mathrm{K} \\
(\sim 23.3 \% \text { deviation })\end{array}$ & $\begin{array}{c}42.02 \mathrm{~mW} / \mathrm{m} . \mathrm{K} \\
(\sim 18 \% \text { deviation })\end{array}$ & $\begin{array}{c}41.24 \mathrm{~mW} / \mathrm{m} . \mathrm{K} \\
(\sim 4.9 \% \text { deviation })\end{array}$ \\
\hline
\end{tabular}

\section{CONCLUSION}

This study focused on numerical and experimental investigation of expanded perlite based heat insulation panels. It can be concluded that;

Five different theoretical thermal conductivity prediction models were used in this study. Generally, a good agreement was observed between the experimentally measured thermal conductivity results and the theoretical thermal conductivity prediction model results. This result showed that the theoretical prediction models can be used in preparation of the mortar before manufacturing stage.

The lowest thermal conductivity value of heat insulation panels was obtained experimentally for sample 4 mixture (vol.94-96\% E.P+ vol.4-6\% binder). The value is $43.5 \mathrm{~mW} / \mathrm{m} . \mathrm{K}$. Developed panel can be used in heat insulation applications.

As a results of theoretical prediction models, the closest model to the experimental results is the parallel model whose average deviation is $4.22 \%$ while the farthest model is the Cheng and Vachon model whose average deviation is $12.43 \%$. As a result, the thermal conductivity of the panels containing expanded perlite can be calculated by the parallel method.

However, the use of these models in different mixtures and materials should be investigated in future studies.

On the other hand, new thermal conductivity prediction model/models which do not neglect processing conditions could be improved.

Finally, next studies should be done by considering these parameters (like curing conditions, pressing force) and the thermal conductivity of the heat insulation panels could be determined without wasting materials. 


\section{ACKNOWLEDGMENTS}

This study was supported by the Scientific and Technological Research Council of Turkey (Project no: 115M041). We are indebted to TÜBİTAK for its financial support.

\section{NOMENCLATURE}

$\begin{array}{ll}\mathrm{K}_{\mathrm{d}} & \text { Thermal conductivity of composite }(\mathrm{W} / \mathrm{m} . \mathrm{K}) \\ \mathrm{k}_{\mathrm{s}} & \text { Thermal conductivity of matrix }(\mathrm{W} / \mathrm{m} . \mathrm{K}) \\ \mathrm{k}_{\mathrm{d}} & \text { Thermal conductivity of fiber }(\mathrm{W} / \mathrm{m} \cdot \mathrm{K}) \\ \mathrm{V}_{\mathrm{d}} & \text { TVolumetric ratio of matrix } \\ \mathrm{R} & \text { The function uncertainty } \\ \mathrm{V}_{\mathrm{M}} & \text { Maximum packing rate of the fill phase } \\ \mathrm{W} & \text { Dimensional shape factor } \\ \mathrm{W}_{\mathrm{R}} & \text { The total uncertainty, \% } \\ \mathrm{W}_{1}, \mathrm{w}_{2}, \mathrm{~W}_{\mathrm{n}} & \text { The uncertainties in the independent variables } \\ \mathrm{x} & \text { Independent variables } \\ \varepsilon & \text { Volumetric ratio of fiber } \\ \mathrm{C} & \text { Ratio of the phase }\end{array}$

\section{REFERENCES}

[1] Baetens, R., Jelle, B. P., Gustavsen, A., Grynning, S. (2010). Gas-filled panels for building applications: A state-of-the-art review. Energy and Buildings, 42(11), 1969-1975.

[2] Mladenovič, A., Šuput, J. S., Ducman, V., Škapin, A. S. (2004). Alkali-silica reactivity of some frequently used lightweight aggregates. Cement and Concrete Research, 34(10), 1809-1816.

[3] Arifuzzaman, M., Kim, H. S. (2014). Development of new perlite/sodium silicate composites. In International Conference on Mechanical, Industrial and Energy Engineering (ICMIEE), Khulna University of Engineering \& Technology, Khulna, Bangladesh, 26-27.

[4] Tian, Y. L., Guo, X. L., Wu, D. L., Sun, S. B. (2013). A study of effect factors on sodium silicate based expanded perlite insulation board strength. In Applied Mechanics and Materials, 405, 2771-2777

[5] Dube, W. P., Sparks, L. L., Slifka, A. J. (1991). Thermal conductivity of evacuated perlite at low temperatures as a function of load and load history. Cryogenics, 31(1), 3-6.

[6] Arifuzzaman, M., Kim, H. S. (2015). Novel mechanical behaviour of perlite/sodium silicate composites. Construction and Building Materials, 93, 230-240.

[7] Owusu, Y. A. (1982). Physical-chemistry study of sodium silicate as a foundry sand binder. Advances in colloid and interface science, 18(1-2), 57-91.

[8] Skubic, B., Lakner, M., Plazl, I. (2012). Microwave drying of expanded perlite insulation board. Industrial \& Engineering Chemistry Research, 51(8), 3314-3321.

[9] Al-Homoud, M. S. (2005). Performance characteristics and practical applications of common building thermal insulation materials. Building and environment, 40(3), 353-366.

[10] Papadopoulos, A. M. (2005). State of the art in thermal insulation materials and aims for future developments. Energy and Buildings, 37(1), 77-86.

[11] Kylili, A., Fokaides, P. A. (2017). Methodologies for selection of thermal insulation materials for costeffective, sustainable, and energy-efficient retrofitting. In Cost-Effective Energy Efficient Building Retrofitting (pp. 23-55).

[12] Pargana, N., Pinheiro, M. D., Silvestre, J. D., de Brito, J. (2014). Comparative environmental life cycle assessment of thermal insulation materials of buildings. Energy and Buildings, 82, 466-481.

[13] Taherishargh, M., Belova, I. V., Murch, G. E., Fiedler, T. (2014). On the mechanical properties of heat-treated expanded perlite-aluminium syntactic foam. Materials \& Design, 63, 375-383.

[14] Binici, H., Kalayc1, F. (2015). Production of perlite based thermal insulating material. International Journal of Academic Research and Reflection, 3(7).

[15] Argunhan, Z., Oktay, H., Dogmus, R. (2016). Investigation of the thermal and acoustic performance of perlite based building materials. European Journal of Technic 6(1):26-36

[16] Topçu, İ. B., Iş̧ıdağ, B. (2008). Effect of expanded perlite aggregate on the properties of lightweight concrete. Journal of Materials Processing Technology, 204(1-3), 34-38.

[17] Demirboğa, R., Gül, R. (2003). Thermal conductivity and compressive strength of expanded perlite aggregate concrete with mineral admixtures. Energy and Buildings, 35(11), 1155-1159.

[18] Çelik, A., Kiliç, A., Akkurt, F. (2014). Yapi malzemesi üretiminde genleştirilmiş perlit agregasi kullanilabilirliğinin araştirilmasi. Gazi Üniversitesi Mühendislik-Mimarlık Fakültesi Dergisi, 29(3).

[19] Vaou, V., Panias, D. (2010). Thermal insulating foamy geopolymers from perlite. Minerals Engineering, 23(14), 1146-1151. 
[20] Gharzouni, A., Joussein, E., Samet, B., Baklouti, S., Rossignol, S. (2015). Effect of the reactivity of alkaline solution and metakaolin on geopolymer formation. Journal of Non-Crystalline Solids, 410, 127-134.

[21] Ikeda, K. (1998). Consolidation of Mineral Powders by the Geopolymer Binder Technique for Material Use. Shigen-to-sozai, 114, 497-500.

[22] Shastri, D., Kim, H. S. (2014). A new consolidation process for expanded perlite particles. Construction and Building Materials, 60, 1-7.

[23] Astutiningsih, S., Liu, Y. (2005, June). Geopolymerisation of Australian slag with effective dissolution by the alkali. In Proceedings of the World Congress Geopolymer (pp. 69-73). Saint Quentin, France.

[24] Tian, Y. L., Guo, X. L., Wu, D. L., Sun, S. B. (2013). A Study of Effect Factors on Sodium Silicate Based Expanded Perlite Insulation Board Strength. In Applied Mechanics and Materials, 405, 2771-2777.

[25] Skubic, B., Lakner, M., Plazl, I. (2013). Sintering behavior of expanded perlite thermal insulation board: modeling and experiments. Industrial \& Engineering Chemistry Research, 52(30), 10244-10249.

[26] State Planning Organization, Building Materials III (pumice-pearlite-Vermiculite Phologopite-expanded Killer) the 8th Five-Year Development Plan Sub-Commission on Industrial Raw Materials hoc Committee Report. 2004, 24-49

[27] Bart, G. C. J. (1994). Thermal conduction in non-homogeneous and phase change media (Doctoral dissertation, TU Delft, Delft University of Technology).

[28] Maqsood, A., \& Kamran, K. (2005). Thermophysical properties of porous sandstones: measurements and comparative study of some representative thermal conductivity models. International Journal of Thermophysics, 26(5), 1617-1632.

[29] Cernuschi, F., Ahmaniemi, S., Vuoristo, P., \& Mäntylä, T. (2004). Modelling of thermal conductivity of porous materials: application to thick thermal barrier coatings. Journal of the European Ceramic Society, 24(9), 26572667.

[30] Maxwell, J.C., A Treatise on Electricity and Magnetism (third ed). 1954 New York (USA): Dover Publications Inc.

[31] Beck, A. E. (1976). An improved method of computing the thermal conductivity of fluid-filled sedimentary rocks. Geophysics, 41(1), 133-144.

[32] Carson, J. K., Lovatt, S. J., Tanner, D. J., Cleland, A. C. (2003). An analysis of the influence of material structure on the effective thermal conductivity of theoretical porous materials using finite element simulations. International Journal of Refrigeration, 26(8), 873-880.

[33] Carson, J. K., Lovatt, S. J., Tanner, D. J., Cleland, A. C. (2003). An analysis of the influence of material structure on the effective thermal conductivity of theoretical porous materials using finite element simulations. International Journal of Refrigeration, 26(8), 873-880.

[34] Carson, J. K. (2006). Review of effective thermal conductivity models for foods. International Journal of Refrigeration, 29(6), 958-967.

[35] Belova, I. V., Murch, G. E. (2004). Monte Carlo simulation of the effective thermal conductivity in two-phase material. Journal of Materials Processing Technology, 153, 741-745.

[36] Carson, J. K., Lovatt, S. J., Tanner, D. J., Cleland, A. C. (2006). Predicting the effective thermal conductivity of unfrozen, porous foods. Journal of Food Engineering, 75(3), 297-307.

[37] Landel, R. F., Nielsen, L. E. (1993). Mechanical properties of polymers and composites. CRC press.

[38] Nielsen, L.E., Mechanical Properties of Polymers and Composites (2). 1974, New York: Marcel Dekker.

[39] Cheng, S. C., Vachon, R. I. (1970). A technique for predicting the thermal conductivity of suspensions, emulsions and porous materials. International Journal of Heat and Mass Transfer, 13(3), 537-546.

[40] Özdemir, M. B., Aktaş, M., Şevik, S., Khanlari, A. (2017). Modeling of a convective-infrared kiwifruit drying process. International Journal of Hydrogen Energy, 42(28), 18005-18013. 